\title{
Anticoagulation after mechanical aortic valve implantation: is it time to act after PROACT?
}

\author{
Mevlüt Çelik, Andras P. Durko, Stuart J. Head \\ Department of Cardiothoracic Surgery, Erasmus University Medical Center, Rotterdam, The Netherlands \\ Correspondence to: Stuart J. Head, MD, PhD. Department of Cardiothoracic Surgery, Erasmus University Medical Center, Rotterdam, The \\ Netherlands. Email: s.head@erasmusmc.nl. \\ Provenance: This is an invited Editorial commissioned by Section Editor Busheng Zhang (Department of Cardiac Surgery, Shanghai Chest Hospital, \\ Shanghai Jiaotong University, Shanghai, China). \\ Comment on: Puskas JD, Gerdisch M, Nichols D, et al. Anticoagulation and Antiplatelet Strategies After On-X Mechanical Aortic Valve Replacement. \\ J Am Coll Cardiol 2018;71:2717-26.
}

Submitted Aug 24, 2018. Accepted for publication Sep 07, 2018.

doi: $10.21037 /$ atm.2018.09.08

View this article at: http://dx.doi.org/10.21037/atm.2018.09.08

Anticoagulation management after mechanical prosthetic heart valve (PHV) implantation should find the delicate balance between effectively preventing valve-related thromboembolic events while not substantially increasing the risk of bleeding (1). Mechanical PHVs traditionally require lifelong anticoagulation with vitamin $\mathrm{K}$ antagonists (VKAs). VKAs have a narrow therapeutic range, a delayed on- and offset of action, and their effect is influenced by dietary vitamin $\mathrm{K}$ intake and numerous drug interactions, which necessitates high patient compliance and lifelong monitoring of the international normalized ratio (INR) (2). Moreover, there is a considerable life-time bleeding risk associated with VKAs, especially considering that the time spent in the therapeutic range (TTR) might be as low as $50 \%$ in some cases (3). The wish to avoid longterm anticoagulation is reflected in the recent trends of PHV utilization, favoring biological over mechanical valves despite their inferior long-term durability (4). However, efforts are made to reduce the intensity and burden of anticoagulation after mechanical heart valve implantation (5-7) or to completely replace VKAs with alternative antithrombotic therapy in patients that do require a mechanical valve (8). Another potential advancement that could completely eliminate the use of VKAs would be the development of novel mechanical heart valves not requiring anticoagulation $(9,10)$. The $\mathrm{On}-\mathrm{X}$ valve (Cryolife, Kennesaw, GA, USA) is designed with the intention to promote physiological blood flow and low thrombogenicity after mechanical PHV implantation by using a silicon-free pyrolytic carbon and allowing for 90-degrees leaflet opening (11).

In a recent article, Puskas and colleagues reported longterm follow-up of the PROACT (Prospective Randomized On-X Anticoagulation Clinical Trial) study, which investigated the non-inferiority of a lowered target INR (range 1.5 to 2.0 ) combined with low-dose acetylsalicylic acid ("high-risk arm") or dual antiplatelet therapy (DAPT, "low-risk arm") over standard anticoagulation with warfarin in patients undergoing mechanical aortic valve replacement (AVR) with the On-X valve (12). The investigational therapy commenced 3 months after surgery, following a period of formal anticoagulation. PROACT enrolled 576 participants ( $\mathrm{n}=375$ in the high-risk arm and $\mathrm{n}=201$ in the low-risk arm) and the primary endpoint of the study was the composite of major and minor bleeding, thromboembolic events, and valve thrombosis. Interim results of the PROACT highrisk arm were already published in 2014 (5), and played a major role in the regulatory approval of the lowered target INR range labeling claim by $\mathrm{On}-\mathrm{X}$. These results were also incorporated in the most recent American clinical practice guidelines on the management of valvular heart disease (13). This final report includes extended follow-up of the highrisk patients, and reports outcomes of the low-risk arm.

In the high-risk arm, the incidence of the combined primary endpoint was $5.50 \%$ per patient-year (\%/py) versus $9.35 \% / p y(P=0.002)$ in patients receiving reduced and standard intensity anticoagulation, respectively. The incidence of bleeding was lower with reduced versus standard intensity warfarin $(2.86 \% /$ py vs. $7.43 \% / \mathrm{py}$, 
respectively; $\mathrm{P}<0.001)$, without affecting the incidences of valve thrombosis $(0.21 \% /$ py vs. $0.18 \% /$ py; $\mathrm{P}=0.90)$, stroke $(0.74 \%$ /py vs. $0.64 \% / \mathrm{py} ; \mathrm{P}=0.80)$, transient ischemic attack $(1.27 \% /$ py vs. $1.01 \% /$ py; $\mathrm{P}=0.60)$, peripheral thromboembolism $(0.42 \% /$ py vs. $0.09 \% / \mathrm{py} ; \mathrm{P}=0.20)$ or all cause-mortality $(1.38 \% / p y$ vs. $1.56 \% / \mathrm{py} ; \mathrm{P}=0.70)$ in patients with reduced and standard anticoagulation, respectively. We performed additional analyses to calculate the incidence rate and rate ratio of all the thromboembolic events (neurological events, peripheral thromboembolic events, and valve thrombosis combined) in the high-risk arm: the incidence of thromboembolic events was $2.64 \%$ /py versus $1.92 \%$ /py (rate ratio: $1.37,95 \% \mathrm{CI}, 0.77-2.45 ; \mathrm{P}=0.28$ ) in patients receiving reduced and standard intensity anticoagulation, respectively. In the low-risk arm, the incidence of thromboembolic events was significantly higher in patients receiving DAPT versus standard anticoagulation (4.86\%/py vs. $0.29 \% /$ py, respectively; $\mathrm{P}=0.02$ ), while no difference in the incidence of bleeding between the two groups was noted (3.82\%/py vs. $3.49 \% /$ py, respectively; $\mathrm{P}=0.80)$.

This report reinforces the safety of lowered INR ranges after mechanical AVR with the On-X valve. However, we cannot exclude the possibility that the safety of a lowered INR range after mechanical AVR might also apply to other modern bileaflet mechanical PHVs. Indeed, there are no studies comparing thromboembolic risk between different modern bileaflet mechanical PHVs. Nevertheless, several studies have been published supporting this notion $(6,7,14,15)$. Recently, a post-hoc analysis of the LOWERING-IT (LOWERing the INtensity of oral anticoaGulant Therapy in patients with bileaflet mechanical aortic valve replacement) trial that focused on 292 patients receiving LivaNova Bicarbon mechanical aortic valves (LivaNova, London, United Kingdom) concluded that a lowered INR target (INR range 1.5 to 2.5 ) was equally safe in terms of thromboembolic complications when compared to standard anticoagulation (INR range 2.0 to 3.0), while significantly less bleeding events occurred in the low INR group (14). In the ESCAT III (Early Self-Controlled Anticoagulation Trial) study, a lower INR target (INR range 1.6 to 2.1) with self-management was found to be superior when compared to standard anticoagulation (INR range 1.8 to 2.8) in terms of bleeding risk, and comparable in terms of thrombotic risk in a large cohort undergoing mechanical AVR, mostly receiving St Jude valves (Abbott, Chicago, IL, USA) (7).

Despite these positive findings in the high-risk arm, the results for the low-risk arm were less assuring. Although previous data suggested that thromboembolic events after mechanical PHV implantation are linked to platelet activation (16) and might be prevented with the use of DAPT (17), the PROACT low-risk arm that investigated DAPT versus standard anticoagulation had to be terminated due to an excess in thromboembolic events in the DAPT group without a benefit in terms of bleeding rates. Of note, the previous CAPTA (Clopidogrel and Aspirin in the Prevention of Thromboembolic Complications After Mechanical Aortic Valve Replacement) study, enrolling 200 patients to compare DAPT with warfarin in mechanical AVR, was stopped prematurely due to similar reasons (18). Even though the design of the On-X valve is believed to be less thrombogenic as compared with many other valves used in the CAPTA trial (11), exclusive antiplatelet therapy with aspirin and clopidogrel still does not appear to be safe after mechanical AVR with the On-X valve. However, novel antiplatelet drugs-ticagrelor and prasugrel—have proven to be more effective when compared to clopidogrel in patients with coronary artery disease $(19,20)$, and it needs to be determined whether these more potent $\mathrm{P} 2 \mathrm{Y} 12$-inhibitors in combination with aspirin may potentially have a role as antithrombotic therapy in a population of patients with mechanical PHVs.

The PROACT study has some aspects to consider when interpreting the result. Firstly, due to the relatively low number of participants and the choice of the composite endpoint (grouping two clinical events that move in opposite directions, e.g., bleeding and thrombosis), the design and statistical power of the study have been questioned (5). Secondly, in the high-risk arm, 22 patients $(12 \%)$ in the lowered INR group suffered a thromboembolic event that required cross-over to standard anticoagulation. In realworld clinical practice, it will be crucial to identify which patients are at risk of a thromboembolic event with a lower INR range before reducing the intensity of anticoagulation. Thirdly, in the PROACT high-risk arm, a combination of warfarin and aspirin was tested and not a lowered dose of warfarin alone. Therefore, it is unclear whether the findings of PROACT would also be applicable for lowered warfarin dosage alone. Finally, all patients assigned to receive warfarin in the PROACT study received an INR testing device for weekly self-monitoring $(7,21)$. This setup is ideal to optimize INR control and increase patient comfort (22), but makes it difficult to extrapolate the study results to a population that does not monitor INR at home since self-monitoring might have an additional protective 
effect by increasing patients' consciousness and compliance with the anticoagulation therapy.

In conclusion, the PROACT study adds to the growing body of evidence of the feasibility of a lowered INR range in high-risk patients undergoing mechanical AVR with the On-X valve. However, these lower INR targets are safe in a strategy with concomitant aspirin therapy and with selfmonitoring INR values, and it is imperative to note that new studies are required before the 1.5-2.0 INR range can be adopted without aspirin therapy or with less rigorous INR-monitoring. Further studies will add to the growing knowledge of the feasibility of a lowered target INR range after mechanical AVR other than the On-X valve (clinicaltrials.gov identifier: NCT03636295). However, it appears that eliminating anticoagulation completely is not safe and is not an acceptable strategy, even in low-risk patients.

\section{Acknowledgements}

None.

\section{Footnote}

Conflicts of Interest: The authors have no conflicts of interest to declare.

\section{References}

1. Head SJ, Celik M, Kappetein AP. Mechanical versus bioprosthetic aortic valve replacement. Eur Heart J 2017;38:2183-91.

2. Shameem R, Ansell J. Disadvantages of VKA and requirements for novel anticoagulants. Best Pract Res Clin Haematol 2013;26:103-14.

3. Poli D, Antonucci E, Pengo V, et al. Mechanical prosthetic heart valves: Quality of anticoagulation and thromboembolic risk. The observational multicenter PLECTRUM study. Int J Cardiol 2018;267:68-73.

4. Isaacs AJ, Shuhaiber J, Salemi A, et al. National trends in utilization and in-hospital outcomes of mechanical versus bioprosthetic aortic valve replacements. J Thorac Cardiovasc Surg 2015;149:1262-9.e3.

5. Puskas J, Gerdisch M, Nichols D, et al. Reduced anticoagulation after mechanical aortic valve replacement: interim results from the prospective randomized on- $X$ valve anticoagulation clinical trial randomized Food and Drug Administration investigational device exemption trial. J Thorac Cardiovasc Surg 2014;147:1202-10; discussion 1210-1.

6. Koertke H, Zittermann A, Tenderich G, et al. Low-dose oral anticoagulation in patients with mechanical heart valve prostheses: final report from the early self-management anticoagulation trial II. Eur Heart J 2007;28:2479-84.

7. Koertke H, Zittermann A, Wagner O, et al. Telemedicineguided, very low-dose international normalized ratio selfcontrol in patients with mechanical heart valve implants. Eur Heart J 2015;36:1297-305.

8. Eikelboom JW, Connolly SJ, Brueckmann M, et al. Dabigatran versus warfarin in patients with mechanical heart valves. N Engl J Med 2013;369:1206-14.

9. Triflo Medical. Available online: www.novostia.com (16 August 2018) [database on the Internet].

10. Scotten LN, Siegel R. Are anticoagulant independent mechanical valves within reach-fast prototype fabrication and in vitro testing of innovative bi-leaflet valve models. Ann Transl Med 2015;3:197.

11. CryoLife. Available online: www.cryolife.com (16 August 2018) [database on the Internet].

12. Puskas JD, Gerdisch M, Nichols D, et al. Anticoagulation and Antiplatelet Strategies After On-X Mechanical Aortic Valve Replacement. J Am Coll Cardiol 2018;71:2717-26.

13. Nishimura RA, Otto CM, Bonow RO, et al. 2017 AHA/ ACC Focused Update of the 2014 AHA/ACC Guideline for the Management of Patients With Valvular Heart Disease: A Report of the American College of Cardiology/ American Heart Association Task Force on Clinical Practice Guidelines. Circulation 2017;135:e1159-95.

14. Torella M, Aquila I, Chiodini P, et al. Low-dose anticoagulation after isolated mechanical aortic valve replacement with Liva Nova Bicarbon prosthesis: A post hoc analysis of LOWERING-IT Trial. Sci Rep 2018;8:8405.

15. Torella M, Torella D, Chiodini P, et al. LOWERing the INtensity of oral anticoaGulant Therapy in patients with bileaflet mechanical aortic valve replacement: results from the "LOWERING-IT" Trial. Am Heart J 2010;160:171-8.

16. Becker RC, Eisenberg P, Turpie AG. Pathobiologic features and prevention of thrombotic complications associated with prosthetic heart valves: fundamental principles and the contribution of platelets and thrombin. Am Heart J 2001;141:1025-37.

17. Garcia-Rinaldi R. Antiplatelet therapy as sole anticoagulant in patients with aortic mechanical prostheses. J Thorac Cardiovasc Surg 2014;148:3255-6. 


\section{Page 4 of 4}

18. Schlitt A, von Bardeleben RS, Ehrlich A, et al. Clopidogrel and aspirin in the prevention of thromboembolic complications after mechanical aortic valve replacement (CAPTA). Thromb Res 2003;109:131-5.

19. Wallentin L, Becker RC, Budaj A, et al. Ticagrelor versus clopidogrel in patients with acute coronary syndromes. $\mathrm{N}$ Engl J Med 2009;361:1045-57.

20. Wiviott SD, Braunwald E, McCabe CH, et al. Prasugrel versus clopidogrel in patients with acute coronary syndromes. N Engl J Med 2007;357:2001-15.

Cite this article as: Çelik M, Durko AP, Head SJ. Anticoagulation after mechanical aortic valve implantation: is it time to act after PROACT? Ann Transl Med 2018;6(Suppl 1):S16. doi: 10.21037/atm.2018.09.08

\section{Çelik et al. Anticoagulation in mechanical aortic prostheses}

21. Matchar DB, Love SR, Jacobson AK, et al. The impact of frequency of patient self-testing of prothrombin time on time in target range within VA Cooperative Study \#481: The Home INR Study (THINRS), a randomized, controlled trial. J Thromb Thrombolysis 2015;40:17-25.

22. Sawicki PT. A structured teaching and self-management program for patients receiving oral anticoagulation: a randomized controlled trial. Working Group for the Study of Patient Self-Management of Oral Anticoagulation. JAMA 1999;281:145-50. 